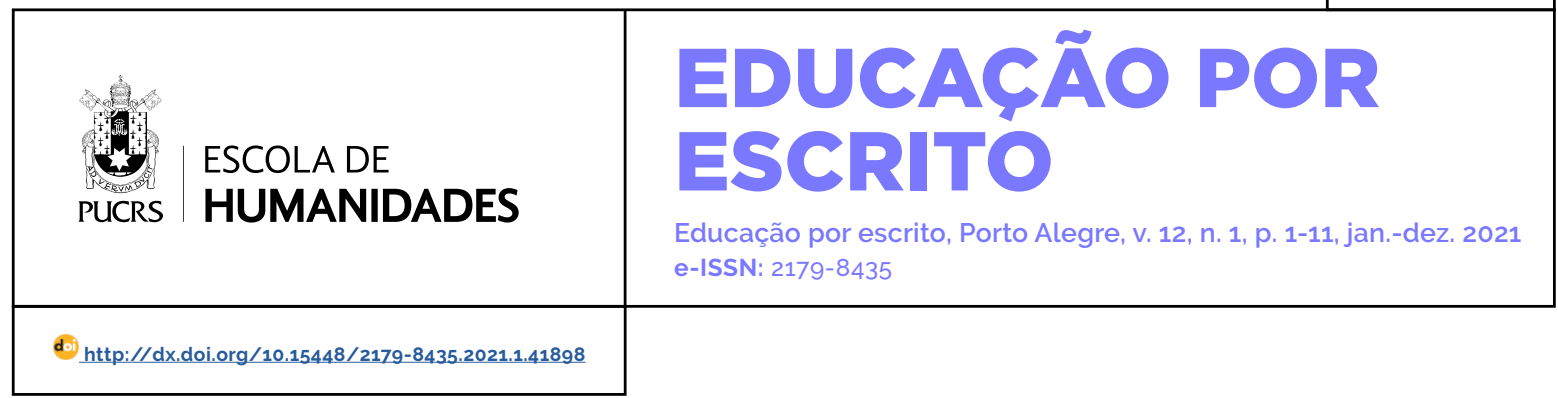

SEÇÃO: A FORMAÇÃO DE PROFESSORES E A EDUCAÇÃO INCLUSIVA: AVANÇOS, DESAFIOS E PERSPECTIVAS

\title{
As implicações das estratégias de motivação no Atendimento Educacional Especializado para a aprendizagem de alunos com deficiência intelectual em atividades da linguagem escrita em contexto digital
}

The implications of motivational strategies in Specialized Educational Service for the involvement of students with intellectual disabilities in written language activities in a digital context

Camila Barreto Silva ${ }^{1}$

orcid.org/0000-0002-9656-7751 camila.barreto@educacao. $\underline{\text { fortaleza.ce.gov.br }}$

\section{Rita Vieira De}

Figueredo²

orcid.org/0000-0003-4167-141X aee.rira@gmail.com

Recebido em: 30/09/2021. Aprovado em: $12 / 11 / 2021$. Publicado em: 23/12/2021.
Resumo: O presente estudo teve por objetivo analisar as implicações de estratégias de motivação desenvolvidas por quatro professoras do Atendimento Educacional Especializado para a implicação significativa de oito estudantes com deficiência intelectual na resolução de problemas em contexto de software educativo. A investigação de natureza qualitativa do tipo pesquisa-ação foi realizada em quatro escolas da rede municipal de Fortaleza. Foram realizados oito procedimentos de coleta de dados, contudo, para a análise, nos reportaremos aos dados referentes aos encontros de formação inicial, as 80 sessões de intervenções desenvolvidas nas SRM, e aos encontros de interação entre pesquisadores e professoras. Dentre as estratégias de mediação destacam-se aquelas sobre o apelo à motivação. Essa categoria apresentou baixa emergência nas primeiras sessões de intervenção, mas significativa progressão posterior. Por outro lado, as s estratégias de motivação apresentavam implicações sobre os desempenhos dos alunos, de modo que esses não mais desistissem de realizar as atividades e se sentissem encorajados a se engajar na resolução dos problemas no software. Palavras-chave: Atendimento Educacional Especializado. Estratégias de mediação. Deficiência intelectual. Software educativo.

Abstract: This study aimed to analyze the implications of motivation strategies developed by four teachers of the Specialized Educational Service for the significant involvement of eight students with intellectual disabilities in solving problems in a digital context. The qualitative research of the action research type was carried out in four schools in the municipal network of Fortaleza. Eight data collection procedures were carried out, however, for the analysis we will refer to data referring to the Initial Formation Meetings, to the 80 Intervention Sessions developed in the SRM, to the Interaction Meetings between researchers and teachers. Among the mediation strategies, those on the Appeal to Motivation stand out. Among the mediation strategies, those on the Appeal to Motivation stand out. This category showed low emergence in the first intervention sessions, but showed significant progression later. Motivation strategies had implications on student performance, so that they no longer gave up on performing activities and felt encouraged to engage in solving problems in the software.

Keywords: Specialized Educational Service. Mediation strategies. Intellectual disability. Educational software. 


\section{Introdução}

O presente artigo versa sobre a análise das estratégias de mediação de natureza motivacional empregadas por professoras do Atendimento Educacional Especializado (AEE) junto a alunos com deficiência intelectual em contexto digital. A investigação de cunho qualitativo do tipo pesquisa-ação foi desenvolvida por meio de sessões de intervenções nas Salas de Recursos Multifuncionais (SRM) mediante o uso do software pedagógico Luz do Saber Infantil. As atividades contidas neste software versavam sobre a aquisição da leitura e da escrita, contudo, a organização didática desenvolvida no contexto da presente pesquisa-ação no AEE tinha como meta implementar diferentes estratégias de mediação de modo que os alunos com deficiência intelectual fossem provocados a resolver diferentes situações-problemas. Esse esclarecimento se faz pertinente, uma vez que as atividades desenvolvidas no AEE - e também aquelas realizadas na presente investigação - apresentam natureza diferente das desenvolvidas em sala de aula comum, mas devem estar correlacionadas com os aportes curriculares do cotidiano da escola.

Diante disso, o AEE como serviço da educação especial deve atuar na interface entre os conhecimentos específicos dessa modalidade de ensino e as situações de aprendizagens escolares (BRASIL, 2008, 2009; MACHADO, 2011). Essa premissa visa promover subsídios para a construção de estratégias de ensino e de aprendizagem com vista à inclusão dos alunos com deficiência intelectual (SILVA, OLIVEIRA NETA, 2020). Vale destacar que tais estratégias devem levar em consideração as caracteristicas inerentes no modo particular do funcionamento cognitivo destes estudantes, implicando sobre a adoção de práticas pedagógicas significativas (OLIVEIRA NETA; SILVA, 2017, 2018).

Para tanto, o trabalho do professor do AEE junto aos alunos com deficiência intelectual ocorre de modo complementar à escolarização e não pela substituição dela (BRASIL, 2008), constituindo-se como um serviço que completa as necessidades educativas desses estudantes com a finalidade de que eles construam a autonomia e a independência em diferentes contextos. Assim, identifica, elabora e organiza recursos pedagógicos e de acessibilidade, atendendo às caracteristicas e às necessidades especificas dos mesmos, a fim de garantir o pleno acesso aos conteúdos curriculares em condições de igualdade, possibilitando desta forma a emergência e o exercício da cidadania (BRASIL, 2008, 2020).

O AEE, voltado aos alunos com deficiência intelectual, deve propiciar a construção de estratégias de aprendizagem significativas para que eles se constituam como protagonistas de sua própria aprendizagem (OLIVEIRA NETA, SILVA, 2018, 2020). Para tanto, realiza ações voltadas para os mecanismos de aprendizagem por meio de atividades que provoquem os alunos a refletirem sobre a aprendizagem de conceitos. Essas atividades, por sua vez, se pautam em situações- problemas em que os alunos são provocados a organizar seu pensamento e possam construir estratégias para a resolução de um dado problema (FIGUEIREDO; POULIN; GOMES, 2010a, 2010b). Tais premissas se fazem pertinentes ao atendimento aos alunos com deficiência intelectual visto que eles apresentam particularidades quanto aos aspectos funcionais do processamento cognitivo (BLOCH, 1997; BONETI; SAINT-LAURENT; GIASSON, 1995; FIGUEIREDO; POULIN; GOMES, 2010a; INHELDER, 1963; PAOUR, 1991).

Segundo Inhelder (1963) as pessoas com deficiência intelectual podem apresentar características de um estágio de desenvolvimento anterior, mesmo estando em um estágio posterior àquele. Essa característica se deve a uma "falsa equilibração" durante a constituição dos estágios de desenvolvimento. Esse aspecto, segundo Figueiredo e Poulin (2008, p. 2), pode implicar sobre "uma superposição de estágios ou a permanência em um estágio intermediário de evolução". Segundo os últimos autores tais aspectos podem incidir de modo direto sobre o desempenho dos mecanismos de aprendizagem das pessoas com deficiência intelectual. Esses mecanismos, por sua vez, apresentam implicações sobre a construção de diferentes conhecimentos e na 
aquisição de habilidades de diferentes naturezas. Vale destacar que os mecanismos de aprendizagem estão relacionados à motivação, à memória, à atenção, à metacognição e à transferência de conhecimento (FIGUEREDO, 2012; FIGUEIREDO; POULIN, 2008; FIGUEIREDO; POULIN GOMES, 2010a; SILVA; FIGUEREDO; POULIN, 2021).

A fragilidade na execução dos mecanismos de aprendizagem nas pessoas com deficiência intelectual traz importantes prejuízos diante da resolução de problemas, haja vista que essas pessoas apresentam dificuldades em organizar os procedimentos necessários à elaboração de uma resposta eficaz à situação. Para tanto, repetem estratégias ineficazes, demonstrando não aprender com a experiência não bem-sucedida e, desta maneira, não percebem a necessidade de mudar as estratégias de resolução do problema (FIGUEIREDO; POULIN; GOMES, 2010a, 2010b).

Como consequência a essas sucessivas experiências de fracasso, as pessoas com deficiência intelectual, fazem mais apelo aos meios externos do que aos próprios recursos cognitivos, apoiando-se "mais sobre recursos externos, tais como a opinião de um colega, do que sobre seus próprios recursos cognitivos. Ele é fortemente influenciado pela opinião e pela ação do outro" (FIGUEIREDO; POULIN; GOMES, 2010b, p. 74-75). Tais aspectos provocam a emergência de comportamentos que sugerem baixa confiança em seu próprio desempenho, atitudes de isolamento, baixo investimento em sua própria aprendizagem, culminando na construção de uma imagem distorcida de si mesmo e na desmotivação para se implicar nas atividades.

Em nossa investigação a motivação apresentou um papel de destaque dentre as estratégias de mediação realizadas pelas professoras do AEE junto aos alunos com deficiência intelectual, haja vista que os professores se depararam com situações em que esses alunos se apresentavam desmotivados, em participar, das atividades no software pedagógico, atribuindo o processo de resolução dos problemas à sua respectiva professora. Diante de tais situações, fez-se necessário investir em estratégias de mediação que favorecessem a participação desses alunos de modo que eles construíssem e aprendessem o sentido de sua própria aprendizagem, sentindo-se motivados a aprender.

A motivação é compreendida como um elemento essencial na aprendizagem dos alunos com deficiência intelectual, visto que implica diretamente sobre o desempenho acadêmico e socioafetivo desses alunos, bem como sobre a capacidades deles em atribuir sentido a sua aprendizagem (POULIN; FIGUEIREDO; GOMES, 2010a; OLIVEIRA NETA, 2013; SILVA, 2012, 2016; SILVA; FIGUEREDO; POULIN, 2021).

Diante do pressuposto o presente artigo tem por objetivo analisar as implicações das estratégias de motivação desenvolvidas no Atendimento Educacional Especializado (AEE) para a conquista da autonomia de estudantes com deficiência intelectual em contexto de aprendizagem da linguagem escrita, mediante o uso do software Luz do Saber Infantil.

\section{Procedimentos metodológicos da investigação}

A investigação de natureza qualitativa do tipo pesquisa-ação foi realizada nas Salas de Recursos Multifuncionais de quatro professoras do AEE junto a oito alunos com deficiência intelectual, todos pertencentes à Rede de Ensino Municipal de Fortaleza, Ceará, Brasil. As professoras foram selecionadas mediante dois critérios: apresentar experiência nessa modalidade de ensino e, ser docente de uma SRM com suporte tecnológico necessário à realização da pesquisa, uma vez que se utilizou um software pedagógico. Quanto aos alunos com deficiência intelectual, selecionamos aqueles que apresentavam assiduidade no AEE e encontravam-se em processo de alfabetização, com niveis psicogenéticos de escrita silábico ou silábico-alfabético.

Tanto as professoras quantos os alunos foram identificados com nomenclaturas seguindo a ordem alfabética dos seus nomes. As professoras foram nomeadas como P1, P2, P3 e P4; e os alunos de $A 1$ até $A 8$. Vale informar que as professoras $P 1 e$ $\mathrm{P} 4$ atenderam os alunos $\mathrm{A} 3$ e $\mathrm{A} 2$, respectivamente, 
e as demais (P2 e P3) atenderam cada uma, três alunos, a saber: A4, A6 e A8 (P2); e A1, A5 e A7 (P3), respectivamente.

A pesquisa contou com oito procedimentos de coleta de dados, contudo, para a análise no presente artigo nos reportaremos aos dados referentes aos encontros de formação inicial, às sessões de intervenções desenvolvidas nas SRM, aos encontros de interação entre pesquisadores e professora.

Os encontros de formação inicial tiveram por objetivo construir um espaço formativo entre as professoras do AEE e a equipe de pesquisadores a fim de que refletissem sobre a importância das estratégias de mediação para a aprendizagem dos alunos com deficiência intelectual em contexto de educação especial inclusiva. Esses encontros ocorreram antes das sessões de intervenção com os alunos nas Salas de Recursos Multifuncionais em um período de quatro dias alternados com duração de oito horas. Nesses encontros as professoras eram incentivadas a refletir sobre a prática no contexto do AEE a partir de problematizações mediante a apresentação de diferentes situações de ensino. Também foram provocadas a pensar sobre a prática a partir de estudos dirigidos com temáticas diversas: mecanismos de aprendizagem dos alunos com deficiência intelectual, aprendizagem da linguagem escrita, concepções de mediação e o uso de diferentes estratégias de mediação em contexto de educação especial.

As sessões de intervenções desenvolvidas pelas professoras nas SRM junto aos alunos com deficiência intelectual ocorreram logo após o processo formativo inicial das docentes. Durante essas sessões os alunos eram acompanhados individualmente pelas suas respectivas professoras nas Salas de Recursos Multifuncionais (SRM). Foram desenvolvidas 10 sessões com cada um dos oito alunos, com duração média de 50 minutos, computando 80 sessões de intervenção. Em cada uma dessas sessões era realizada uma das aulas do software Luz do Saber Infantil do módulo Ler. Essas aulas apresentavam temáticas diferentes (brincadeiras, músicas, folclore etc.), um determinado gênero textual (biografia, poesia, reportagem, música, receita etc.) e continham entre 9 e 12 questões.

No decurso dessas sessões as professoras provocavam os alunos a responder e a refletir sobre as questões no software, mediante a emergência de diferentes estratégias de mediação. Todas as 80 sessões foram gravadas em áudio e vídeos para serem utilizadas como material de base para os encontros de interação entre os pesquisadores e professores. Esses, por sua vez, ocorreram a cada duas ou três sessões de intervenção com os alunos nas SRM. Tais encontros, que também tinham natureza formativa, tinham por objetivo analisar e discutir as intervenções das professoras a partir da visualização de trechos dos vídeos de suas sessões.

A visualização destes vídeos possibilitou a reflexão acerca da pertinência (ou não) das estratégias de mediação empregadas pelas quatro professoras para a aprendizagem dos alunos com deficiência intelectual em contexto do AEE. Nesses encontros as professoras também relatavam diferentes elementos à prática, como os conflitos vividos por elas e pelos alunos durante as atividades, as suas conquistas e as dos estudantes, bem como as perspectivas (positivas e/ou negativas) sobre seus próprios desempenhos enquanto sujeitos de aprendizagem em processo formativo.

Após as etapas de coleta de dados, fez-se necessário selecionar algumas das sessões realizadas devido à grande demanda de dados coletados. Diante disso foram selecionadas quatro das 10 sessões de intervenção realizadas com cada um dos oitos alunos, ou seja, foram analisadas 32 sessões das 80 desenvolvidas. Selecionamos a primeira, a terceira, a sexta e a nona seções, sendo intituladas S1, S3, S6, e S9, respectivamente - foram selecionadas as sessões iniciais, intermediárias e finais da pesquisa a fim de possibilitar analisar as estratégias de mediação de modo progressivo ao longo da pesquisa.

A S1 teve como gênero um texto de instrução sobre como brincar de amarelinha; S3 apresentou uma biografia de um jogador de futebol; a S6 constituiu-se uma música infantil popular brasileira intitulada "Fui à Espanha"; e a Sg apresentou 
o gênero piada que contava uma história hilária sobre um papagaio especial.

\section{Análise e discussão das estratégias de mediação: apelo à motivação}

A análise dos vídeos das intervenções permitiu identificar 46 tipos de estratégias de mediação manifestadas pelas professoras dentre as quatro sessões (S1, S3, S6, S9). Para a identificação dessas estratégias nos referendamos sob a perspectiva histórico-cultural (VYGOTSKY, 1991). Essa referência nos permite ver o ser como um sujeito em constante transformação em uma sociedade culturalmente mediada por objetos, fenômenos e pessoas. Para tanto, consideramos como estratégias de mediação todas as ações, recursos ou materiais empreendidos pelas professoras do AEE para mediar os alunos com deficiência intelectual, mediante as situações de resolução de problemas no software educativo.

A frequência total (absoluta) das estratégias de mediação computaram 2.923. Contudo, devido à diferença na quantidade de alunos atendidos dentre as quatro professoras - visto que P2 e P3 atenderam três alunos e as demais somente um - fez-se necessário um novo tratamento estatístico, no qual revelou uma nova frequência: 2.897 .

As 46 estratégias de mediação foram organizadas em sete categorias, dentre as quais apresentaremos a categoria Apelo à motivação. As estratégias dessa categoria centram-se sobre o enunciado de diferentes comentários aos alunos com deficiência de modo que eles se implicassem nas atividades.

As estratégias de mediação do tipo Apelo à motivação obtiveram frequência total e absoluta de 234. Seus dados, apesar de obterem um índice menor dentre as demais categorias, se destacaram pela importância no auxílio à superação de diferentes comportamentos que dificultavam os alunos na realização das atividades. Essas estratégias emergiram em nosso estudo dado a presença de comportamentos de hesitação, de desistência e de atribuição do papel de responder às questões a terceiros.
Dentre as primeiras sessões da pesquisa, seis dos oitos alunos com deficiência intelectual apresentavam dificuldade em iniciar as atividades, recusando-se em realizá-las, ora desistindo das mesmas, ora atribuindo à professora o papel de responder às questões no software. A fim de auxiliar os alunos na superação desses comportamentos as professoras fizeram uso de quatro tipos de estratégias de motivação: comentários positivos sobre o êxito do aluno; motivação inicial para se implicar/engajar na atividade; incentivo baseado na competência do aluno; e motivação com base em recompensa.

Essas estratégias ocorriam por meio de expressões do tipo: "Sei que vc é capaz"; "Você já chegou até aqui não pode desistir, vamos lá"; "Vai, você consegue, mas tem que se concentrar, se você focar vai conseguir!"; "Continue, não é porque esta alternativa não deu certo que você vai desistir"; É você que deve responder, pois é capaz e forte"; "Lembre-se do que já conversamos olhe, tente focar na questão, pense, você pode responder".

De modo geral as estratégias de medição obtiveram baixa frequência em $\mathrm{S} 1$, e progressão importante entre S1 e S3, e S3 e S6.

As estratégias de Apelo à motivação apresentaram baixa emergência em S1 e, ao encontro disso, observou-se nesse mesmo período uma alta demanda de comportamentos de hesitação por parte dos alunos quanto à realização das atividades. Esse contexto provocou a retomada da temática motivação nos encontros de interação entre professoras e pesquisadoras promovidos após a S1. Nesse espaço formativo emergiram discussões importantes sobre quais estratégias poderiam contribuir para a superação daqueles comportamentos e como essas estratégias poderiam auxiliar os alunos na construção do sentido de sua aprendizagem.

A visualização de trechos dos vídeos das sessões de intervenção nos encontros de interação foi de suma importância para a tomada de reflexão da prática pelas professoras quanto à construção de um ambiente significativo para os alunos com deficiência intelectual de modo que 
eles se implicassem nas atividades, sentindo-se motivados a permanecer e dar continuidade aos exercicios. É importante destacar que nesses encontros colocou-se em pauta a estratégia motivação com base em recompensa. Este tipo de estratégia provocava a realização pontual de questões, ou seja, ela era utilizada apenas com o objetivo de que o aluno concluisse a atividade. Vale salientar que essa estratégia em particular é considerada no presente estudo como menos eficaz, visto que não provocava nos alunos sentimento de pertença àquele contexto de aprendizagem no AEE, não fazia menção às potencialidades necessárias para a realização da atividade e não os impulsionava a permanecerem na atividade de modo significativo, compreendendo que os exercícios poderiam trazer resultados exitosos para sua aprendizagem.

A progressão entre S1 e S3 quanto aos aspectos motivacionais foi observada de modo pouco expressiva na presente pesquisa. Contudo, foi considerada como ponto importante neste estudo por considerarmos que esse fato pode refletir os aportes discutidos nos encontros de interação e nos momentos de formação inicial. Vale lembrar que um dos mecanismos de aprendizagem tratados nesta formação foi a motivação dos alunos com deficiência intelectual, e a construção de estratégias de mediação que possibilitassem a esses alunos se implicarem nas atividades.

Vale lembrar também que nas formações iniciais discutiu-se junto ao grupo a importância de compreendermos diferentes conceitos, dentre eles o da deficiência intelectual. Para alguns autores esse conceito centra-se sobre cinco aspectos, dentre eles sobre a fragilidade quanto ao comportamento adaptativo (GAGNON, 2014; SCHALOCK; BORTHWICK-DUFFY; BRADLEY; BUNTINX; CRAIG, 2010). Segundo Schalock et al., (2010), p. 43, tradução nossa) o comportamento adaptativo se constitui por um "conjunto de habilidades conceituais, sociais e práticas aprendidas pela pessoa e que the permite funcionar no dia a dia". Segundo Gagnon (2014), esse conceito apresenta implicações significativas sobre a construção de habilidades sociais, conceituais e práticas; além disso explica que para a emergência dessas habilidades devemos levar em consideração o ambiente cultural e os aspectos motivacionais implicados neste contexto.

Em nossa pesquisa, apresentar estratégias de mediação em contexto de Atendimento Educacional Especializado que implicassem na motivação dos alunos de modo sistemático e reflexivo se constituiu como fator preponderante. A emergência de estratégias desse tipo desde o inicio das sessões pode ter fomentado a participação dos estudantes com deficiência intelectual nas sessões seguintes, como evidenciam os dados entre S6 e S9, os quais demonstram uma importante progressão.

De modo particular vale destacar que P4 não computou dados quanto às estratégias de mediação de motivação em S1, contudo demonstrou a emergência dessas em S3, duplicando seus dados em S6. P2, por sua vez, apresentou maiores dados dentre as quatro professoras em S3 e S6, principalmente junto ao A8.

Esse aluno (A8) em S1 e em meados da S3 não se implicava na atividade, apresentava baixa concentração, desistia da atividade com facilidade, apresentava comportamentos que sugeriam baixa autoestima, sendo necessários estímulos constantes para iniciar a atividade e para permanecer nela - comportamentos dessas naturezas foram observados em outros alunos de P2 e, também, naqueles atendidos por P3.

Vale destacar que no decorrer das demais sessões os alunos de P2 e P3 apresentaram um importante avanço quanto à permanência nas atividades, realizando com êxito muitas das questões de leitura e de escrita, principalmente, aquelas com propostas mais complexas. Observou-se que, na medida em que as estratégias comentários positivos sobre o êxito do aluno e incentivo baseado na competência eram enunciadas pelas professoras, o desempenho dos alunos - principalmente os de A8 e A2 - aumentavam ao longo das sessões. Esses alunos, além de não mais precisarem de estratégias para se implicar nas atividades, cobravam das professoras felicitações pelos seus trabalhos, o que demonstra 
a assimilação dessas estratégias de mediação pelos alunos, como mostra a situação ${ }^{3}$ abaixo quando A8 acerta a questão e a professora (P2) prossegue:

- "o que foi, vamos para a próxima questão?" (P2, informação verbal).

- "tia tu nem disse parabéns, eu acertei sabia?!" (A8, informação verbal).

A fala do aluno parece demonstrar que a felicitação pelo reconhecimento do seu desempenho era aspecto condicional para prosseguimento das atividades. Isso implica na construção de sentido do seu desempenho por isso corrobora-se com Figueiredo, Poulin e Gomes (2010, p. 28) quando afirmam que as atividades no contexto do Atendimento Educacional Especializado devem "reunir tarefas exequiveis que possibilitem o aluno se vincular com o êxito da atividade proposta pelo professor. A motivação é muito importante, pois está inter-relacionada com a capacidade de atribuir sentido a atividade". Segundo os autores as pessoas com deficiência intelectual apresentam dificuldade sobre o plano socioafetivo, especialmente, quanto à construção da imagem de si mesmo - essa premissa é inspirada nos pressupostos de Sahuc (2006). As experiências sociais e de interação que não obtiveram sucesso incidem como fatores que contribuem para a solidez dessas dificuldades. Ainda de acordo com os autores, comportamentos de baixa autoestima - como observamos nos sujeitos de nosso experimento - podem interferir na motivação desses alunos em diferentes contextos, dentre eles quando estão em situação resolução de problemas e/ou de aprendizagem.

Dados semelhantes às estratégias de apelo à motivação utilizando comentários positivos foram evidenciados em diferentes pesquisas (OLIVEIRA NETA, 2013; PASSERINO, 2005; RODRIGUES, 2018; PASSERINO; GLUZ; VICARI, 2007; SEVERO; LIMA; PASSERINO, 2013), as quais destacam a importância dessas estratégias para maximizar o desempenho dos alunos nas atividades. Em nosso contexto de investigação essas estratégias apresentaram indices significativos durante os momentos em que os alunos eram provocados a realizar a exploração inicial das questões.

De modo a explicitar a dinâmica no interior das atividades, os alunos eram incentivados a explorar os elementos textuais e contextuais dos textos no software, realizando a leitura de diferentes elementos. As estratégias de motivação apresentavam implicações sobre os desempenhos dos alunos, de modo que não mais desistissem de realizar as atividades e sentissem-se encorajados a completar as propostas de leitura e escrita. Com base nisso infere-se que o incentivo à predição no contexto de nossa investigação por meio das inúmeras e gradativas estratégias de motivação podem ter tido implicações sobre a emergência e a ampliação das estratégias de leitura pelos alunos ao longo das sessões, pois, conforme, Coscarelli ([2020]) "antecipar ou predizer o que vai ser lido costuma acontecer em muitos momentos da leitura e costuma tornar essa leitura mais eficiente". O incentivo à predição textual no contexto do AEE por meio de estratégias de motivação pode ser observado no diálogo ${ }^{4}$ a seguir:

\footnotetext{
- "agora vamos iniciar nossa atividade. O que precisamos fazer?" (P2, informação verbal).

- "tenho que pensar" (A8, informação verbal).

- "isso, pensa e responder, sem receio; você é inteligente e vai conseguir também fazer tudo, entao vamos de novo: o que a gente precisa fazer para resolver essa questão?" (P2, informação verbal).

- "descobrir a rima" (A8, informação verbal).

- "e você já sabe onde está?" (P2, informação verbal).
}

A8 olha para a professora.

P2 interrompe o olhar e diz: "não tenha medo de errar todo mundo erra, tenta de novo e acerta. vamos lá (fala o nome do aluno)" (P2, informação verbal).

A8 clica na opção correta.

- "PA-RA-BÉNSS (levanta os braços do aluno vibrando com ele) tá vendo como você con-

\footnotetext{
Diálogo entre A8 e P2 concedido ao grupo de pesquisa LER/UFC, gravado em vídeo durante uma das sessões de intervenção via software educativo em uma SRM localizada em Fortaleza, CE, Brasil, em 1 out. 2018.

4 Diálogo entre A8 e P2 concedido ao grupo de pesquisa LER/UFC, gravado em vídeo durante uma das sessões de intervenção via software educativo em uma SRM localizada em Fortaleza, CE, Brasil, em 31 out. 2018.
} 
segue, muito bem (fala o nome do aluno) você conseguiu sozinho, pensando, PA-RA-BÉNSS... você está vendo o que fez?!" (P2, informação verbal).

- "é tia a gente tem que fazer para ficar inteligente, né, tem que escrever para gente aprender para ficar inteligente" (A8, informação verbal).

É importante destacar que o trabalho do AEE junto aos alunos com deficiência intelectual deve primar pela compreensão dos elementos que motivam esses alunos a aprender, bem como analisar e investigar o modo como eles se relacionam com o saber, visto que essa relação tem uma implicação direta sobre o processo de aprendizagem desse discentes. É importante destacar no contexto do AEE que a relação que o aluno estabelece com o saber deve ser elemento de investigação dentre a elaboração do Estudo de Caso e deve ser avaliado nos diferentes espaços escolares (FIGUEIREDO; POULIN; GOMES, 2010a, 2010b; SILVA; OLIVEIRA NETA, 2020).

Para Figueiredo, Poulin e Gomes (2010b, p. 12) "se este aluno se percebe como sujeito de aprendizagem capaz de contribuir ativamente com a construção de saberes no interior de seu grupo ele certamente terá uma motivação maior na mobilização de seus mecanismos de pensamento".

Zigler (1962) afirma que a compreensão dos propósitos motivacionais é pertinente no contexto da aprendizagem das pessoas com deficiência intelectual, haja vista que, quando o indivíduo não consegue inferir sobre o sentido de uma dada atividade, dificilmente se sentirá motivado a dar início a mesma ou a permanecer nela. Ainda segundo o autor, as pessoas com deficiência intelectual geralmente vivenciam experiências negativas junto às organizações de saúde, sociais e pedagógicas (FIGUEIREDO; POULIN; GOMES, 2010a; FRIELINK; EMBREGTS, 2013; GAGNON, 2014; JAHODA; DAGNAN; JARVIE; KERR, 2006). Essas experiências podem fomentar nessas pessoas impressões de descontrole sobre seu próprio comportamento ou sobre como agir em determinadas situações (FRIELINK; EMBREGTS, 2013: WEHMEYER; BOLDING, 2001). O sentimento de desamparo pode ser o resultado dessas experiências falhas (SELIGMAN; MAIER, 1967) e culminar em uma baixa motivação (GAGNON, 2014; KUNNEN; STEENBEEK, 1999).

Zigler (1962), ainda destaca que estudos que tratam sobre a aprendizagem e a percepção das pessoas com deficiência intelectual devem se atentar para os processos motivacionais dessas pessoas, pois caso os desprezem, encontrarão dificuldades em determinar o nível de desenvolvimento característico desses sujeitos e as implicações significativas para suas aprendizagens.

Por fim, os dados de nossa investigação revelaram que as estratégias de apelo à motivação se fizeram pertinentes, visto que, as estruturas motivacionais das pessoas com deficiência intelectual diferem-se daquelas sem deficiência devido ao seu "déficit intelectual [...] e as experiências sociais atípicas" (ZIGLER, 1962, p. 1). É válido destacar que Figueiredo, Poulin e Gomes (2010a) afirmam que as pessoas com deficiência intelectual demonstram dificuldades de evocação e de representação. Tais dificuldades podem gerar limitações na interiorização da realidade e na emergência de significação, o que implica sobre a capacidade de atribuir sentido às atividades propostas.

Parte-se do pressuposto de que as intervenções do professor do AEE sejam primordiais para que o aluno com esse tipo de deficiência possa dar sentido ao que faz e ao que expressa (FIGUEIREDO; POULIN; GOMES, 2010a). Vale destacar que, essa capacidade nesses sujeitos não se desenvolve de modo espontâneo - devido à fragilidade na execução dos mecanismos de aprendizagem -, sendo necessário estratégias de mediação eficazes para que eles se motivem a se implicar nas diferentes atividades e possam transferir as habilidades construídas para o contexto da sala comum, mas também para fora dela de modo significativo, atribuindo-lhes sentido.

\section{Considerações finais}

O presente estudo teve por objetivo analisar as implicações de estratégias de motivação desenvolvidas por quatro professoras do Atendimento Educacional Especializado para a implicação 
significativa de oito estudantes com deficiência intelectual na resolução de problemas em contexto digital. Essas estratégias versavam sobre o enunciado de comentários positivos sobre o êxito e sobre o desempenho desses alunos, bem como provocavam os alunos a se implicarem de modo significativo na resolução das questões do software Luz do Saber Infantil.

Em nossa investigação, a priori, os alunos com deficiência intelectual apresentaram diferentes comportamentos que dificultavam seu acesso ao software, bem como sua permanência nas atividades, como hesitação, desistência, e baixa autoestima, atribuindo o papel de realizar as atividades à terceiros. Esses comportamentos de natureza socioafetiva podem demonstrar uma particularidade na resposta do funcionamento cognitivo desses estudantes às demandas escolares quanto ao seu desempenho. Diante de tal premissa, fez-se necessário o engajamento das professoras do AEE no sentido de buscar estratégias de mediação que oportunizassem os alunos a encontrar caminhos para a superação desses comportamentos.

Diante desse contexto provocador, as professoras do AEE construiram quatro estratégias de motivação. Essas estratégias incidiam sobretudo, em elucidar os alunos sobre seus papéis no processo de ensino e de aprendizagem como sujeitos ativos que exprimem e constroem hipóteses e, que essas, não devem ser compreendidas como erros, mas sim como elementos primordiais e integrantes desse processo o qual, nunca será linear. Essas estratégias implicavam sobre a construção de sentido de aprendizagem pelos alunos quanto a sua permanência e a construção de saber advinda da resolução das questões.

As estratégias de motivação apresentaram baixa frequência nas primeiras sessões, contudo, na medida em que as professoras se engajaram nas discussões formativas observou-se o aumento na frequência dessas estratégias e, por sua vez, constatou-se uma redução nos comportamentos de hesitação e de desistências das atividades por parte dos alunos. Isso implica afirmar que tais estratégias podem ter impulsionado uma maior participação desses discentes e uma maior implicação desses no levantamento de hipóteses para a exploração das atividades de leitura e escrita no software

Compreendemos, portanto, que as estratégias de motivação empregadas pelas professoras do AEE junto aos alunos com deficiência intelectual na pesquisa não só os impulsionavam a participar das atividades, mas fomentavam neles uma identidade, uma imagem de ser sujeito aprendente e significativo que pode avançar em suas hipóteses e conquistar, assim, novos conhecimentos e saberes.

\section{Referencias}

BLOCH, Silviane Bonaccorsi Barbato. Processo de produção textual de uma jovem com sindrome de Down. 1997. Tese (Doutorado em Educação) - Universidade de Brasília, Brasília, 1997.

BONETI, Rita Vieira de Figueiredo; SAINT-LAURENT, Lise; GIASSON, J. Apprentissage de la lecture: processus reliés à l'interprétation du prénom. Revue franchophone de la déficience intellectuelle, Québec, n. spécial, maio, p. 62-76 1995

BRASIL. Política Nacional de Educação Especial na Perspectiva da Educação Inclusiva. Brasilia: MEC/ SEESP, 2008. Disponivel em: http://portal.mec.gov.br/ index.php?option=com_docman\&view=download\&alias=1669o-politica-nacional-de-educacao-especial-na-perspectiva-da-educacao-inclusiva-05122014\&ltemid=30192. Acesso em: 30 de set. de 2020.

BRASIL. Relatório do $3^{\circ}$ ciclo de monitoramento das metas do Plano Nacional de Educação - 2020. Brasilia: Instituto Nacional de Estudos e Pesquisas Educacionais Anisio Teixeira, 2020.Disponivel em: https://anped.org. $\mathrm{br} / \mathrm{news} /$ relatorio-do-3o-ciclo-de-monitoramento-das-metas-do-plano-nacional-de-educacao-inep. Acesso em: 13 de julho de 2020

BRASIL. Resolução $n^{\circ}$ 4, de 2 de outubro de 2009 Diretrizes Operacionais para o Atendimento Educacional Especializado na Educação Básica, modalidade Educação Especial. Brasilia, DF, 2009. Disponivel em: http://portal.mec.gov.br/dmdocuments/rcebo04_09. pdf. Acesso em: 12 dez. 2020.

COSCARELLI. Carla Viana. Antecipação na leitura (predição). In: MAGDA, Soares. Glosaario CEALI. Centro de Alfabetização, Leitura e Escrita (CEALE) | Faculdade de Educação da UFMG. Belo Horizonte, Minas Gerais. [recurso eletronico]. Disponivel em: http://www.ceale. fae.ufmg.br/app/webroot/glossarioceale/autor/carla-viana-coscarelli. Acesso em: 4 ago. 2020.

FIGUEIREDO, Rita Vieira de. Leitura, Cognição e Deficiência Mental. Fortaleza: Edições UFC, 2012. 
FRIELINK, Noud; EMBREGTS, Petri. Modification of motivational interviewing for use with people with mild intellectual disability and challenging behaviour. Journal of Intellectual \& Developmental Disability, [S. I.], v. 38, n. 4, p. 279-291, 2013.

FIGUEIREDO, Rita Vieira de; POULIN, Jean Robert. Aspectos funcionais do

desenvolvimento cognitivo de crianças com deficiência mental e metodologia de

pesquisa. In: CRUZ, S. H. V. (org.). A criança fala: a escuta de crianças em pesquisa. 1. ed. São Paulo: Cortez, 2008. v. 1, p. 245-263.

FIGUEIREDO, Rita Vieira de; POULIN, Jean Robert; GOMES, Adriana Leite Limaverde. Atendimento Educacional Especializado do aluno com deficiência intelectual. São Paulo: Moderna, 2010a.

FIGUEIREDO, Rita Vieira de; POULIN, Jean Robert; GOMES, Adriana Leite Limaverde. Educação especial na perspectiva da educação inclusiva: atendimento educacional especializado para alunos com deficiência intelectual. Ministério da Educação: Universidade Federal do Ceará, Fortaleza, 2010b.

GAGNON, MARC-ANDRÉ. Étude des facteurs contextuels et motiva tionnels liés aux comportements agressifs de personnes ayant une déficience intellectuelle. Tese (Doutorado em psicologia) - Université Du Québec À Montréal, Canadá, 2014

INHELDER, Bärbel. Le diagnostic du raisonnement chez les débiles mentaux. zième édition augmentée. Neuchâtel (Suisse): Éditions Delachaux \& Niestlé, 1963.

JAHODA, Andrew: DAGNAN, Dave; JARVIE, Pamela; KERR, Wendy. Depression, social context and cognitive behavioural therapy for people who have intellectual disabilities. Journal of Applied Research in Intellectual Disabilities, 1 ed., v. 19, p. 81-89, 2006. Disponivel em: https://onlinelibrary.wiley.com/doi/epdf/10.1111/j. 1468-3148.2005.00286.x. Acesso em: 25 maio 2012.

KUNNEN, E. S.; STEENBEEK, H. W. Differences in problems of motivation in different special groups. Child Care, Health and Development, [S. I.], n. 25, p. 429-446, 1999. Disponivel em: https://pubmed.ncbi.nlm.nih. gov/10547706. Acesso em: 25 out. 2015

MACHADO, Rosângela. Inclusão. Revista Educação Especial, Brasilia, v. 6. n. 1, p. 4-7. jan./jun. 2011.

OLIVEIRA NETA, Adelaide de Sousa. A prática pedagógica do professor de atendimento educacional especializado para o aluno com deficiência intelectual. 2013. Dissertação (Mestrado em Educação Brasileira) - Universidade Federal do Ceará, Fortaleza, 2013.
OLIVEIRA NETA, Adelaide Sousa de; BARRETO-SILVA, Camila. Plano de atendimento educacional especializado e deficiência intelectual: análise de estratégias de inclusão a partir da construção de diferentes parcerias In: OLIVEIRA, Inês Barbosa de. PLETSCH Marcia Denise. PEREIRA, Talita Vidal. RIBEIRO, Yrlla (org.). Didática(s) entre diálogos, insurgências e políticas: tensões e perspectivas na relação entre novas epistemologias, biodiversidade, diferença, democracia e inclusão. 1. ed. Rio de Janeiro/Petrópolis: Faperj; CNPq; Capes; Endipe /DP et Alii, 2020. E-book. Disponivel em: https://drive. google.com/file/d/1i_bww3qun1-gbHBvLkiq_FpCpVQoielc/view. Acesso em: 10 jan. 2021

OLIVEIRA NETA, Adelaide Sousa de; BARRETO-SILVA, Camila. Educação especial e formação de professores: implicações da mediação para a autonomia de alunos com deficiência intelectual: In: ENCONTRO NACIONAL DE DIDÁTICA E PRÁTICAS DE ENSINO, 19., 2018, Bahia. Anais [...]. Bahia, 2018. v. I.

OLIVEIRA NETA, Adelaide Sousa de. BARRETO-SILVA, Camila. Atendimento Educacional Especializado: características e especificidades na avaliação da escrita de alunos com deficiência intelectual. In: CIASCA, Maria Isabel Filgueiras Lima et al. VII Congresso Internacional em Avaliação Educacional Avaliação e Seus Espaços: desafios e reflexões. Fortaleza, Ceará, 2017. p. 13471368. E-book. Disponivel em: http://www.nave.ufc.br/ vii_ciae/wp-content/uploads/2017/03/E_BOOK_VII-CONGRESSO-INTERNACIONAL-EM-AVALIA\%C3\%87\%C3\%83O-EDUCACIONAL_LIVRO-COMPLETO.pdf. Acesso em: 1 fev. 2018.

PAOUR, Jean Robert. Modele cognitif et developmental du retard mental: pour comprendre et intervenir. Université de Provence: Marsille, 1991.

PASSERINO, Liliana M; GLUZ, João Carlos. VICARI; Rosa Maria. MEDIATEC - Mediação Tecnológica em Espaços Virtuais para Apoio ao Professor Online. RENOTE - Revista Novas Tecnologias na Educação, Porto Alegre, v. 5 , n. 1, 2007. Disponivel em: https://seer.ufrgs.br/renote/ article/view/14217. Acesso em: 25 out. 2020.

SAHUC, Caroline. Comprendre son enfant 0-10 ans. Nanterre: Éditeur SA Studyrama, 2006.

SCHALOCK, Robert L.; BORTHWICK-DUFFY, Sharon A.; BRADLEY, Valerie J.; BUNTINX, Wil H. E.; CRAIG, Ellis Pat M. Intellectual Disability: Definition, Classification and Systems of Supports. 2. ed. Washington: American Association on Intellectual and Developmental Disabilities, 2010.

SEVERO, Carlos Emilio Padilla; LIMA, José Valdeni De; PASSERINO, Liliana. Ciência Mediação pedagógica em Ambiente Virtual de Aprendizagem com apoioTecnológico. SÁNCHEZ, Jaime; CAMPOS, Márcia de Borba (ed.). Nuevas Ideas en Informática Educativa TISE. Porto Alegre: PUCRS: Universidad de Chile, 2013. v. 9, p. 204-210. Disponivel em: http://www.tise.cl/volumeng/ TISE2013/204-210.pdf. Acesso em: 10 jan. 2016.

SELIGMAN, M. E.; MAIER, S. F. Failure to escape traumatic shock. Journal of Experimental Psychology, IS. l.], n. 74, p. 1-9, 1967. 
Camila Barreto Silva · Rita Vieira De Figueredo

SILVA, Camila Barreto. A produção escrita de alunos com deficiência intelectual no contexto da mediação em sala de aula. 2012. Dissertação (Mestrado em Educação) - Faculdade de Educação, Programa de Pós-Graduação em Educação Brasileira, Universidade Federal do Ceará, Fortaleza, 2012.

SILVA, Camila Barreto. Aprendizagem cooperativa no contexto da sala comum: a análise da evolução psicogenética da língua escrita de alunos com deficiência intelectual. 2016. Tese (Doutorado em Educação) - Faculdade de Educação, Universidade Federal do Ceará, Fortaleza, 2016.

SILVA, Camila Barreto; OLIVEIRA NETA, Adelaide de Sousa. Saberes e Práticas do Atendimento Educacional Especializado: aportes que fundamentam a prática docente. In: OLIVEIRA NETA, Adelaide de Sousa; SILVA Camila Barreto; MELO NETA, Maria de Holanda (org.). Intercâmbio de saberes e práticas: uma experiência pioneira de formação de professoras do Atendimento Educacional Especializado. Paraná: Editora CRV. 2020. p. 17-22.

SILVA, Camila Barreto; FIGUEREDO, Rita Vieira de; POULIN Jean- Robert. Aprendizagem cooperativa e deficiência intelectual: a conquista

do protagonismo na produção textual. Fortaleza: Imprensa Universitária, 2021. E-book.

ZIGLER. E. Devolopmental versus difference theories of mental retardation and the problem of motivation. American Journal of mental deficiency, [S. I.], v. 73, p. 536-566, 1969

\section{Camila Barreto Silva}

Doutora e mestre em Educação Brasileira pela Universidade Federal do Ceará (UFC), em Fortaleza, CE, Brasil; especialista em Educação Inclusiva pela Universidade 7 de Setembro (UNI7), em Fortaleza, CE, Brasil; pedagoga pela UFC, em Fortaleza, CE, Brasil; professora do Atendimento Educacional Especializado da Secretaria Municipal de Educação da Prefeitura de Fortaleza, CE, Brasil.

\section{Rita Vieira de Figueredo}

Doutora (Ph.D.) em Psicopedagogia pela Université Laval, em Quebec, Canadá; pós-doutorado em Linguagem Escrita e Deficiência Intelectual pela Universidade de Barcelona, em Catalunha, na Espanha. Mestre em Educação pela Universidade Federal do Rio Grande do Sul (UFRGS), em Porto Alegre, RS, Brasil; graduada em Pedagogia pela Universidade Federal do Rio Grande do Norte, em Natal, RN, Brasil.

\section{Endereço para correspondência}

\section{Camila Barreto Silva/ Rita Vieira de Figueredo}

Universidade Federal do Ceará

Rua Waldery Uchôa, 01

Benfica, 60020-110

Fortaleza, CE, Brasil

Os textos deste artigo foram revisados pela Poá Comunicação e submetidos para validação das autoras antes da publicação. 